\title{
Characterization of Staphylococcus pseudintermedius isolated from diseased dogs in Lithuania
}

\author{
M. Ruzauskas ${ }^{1}$, N. Couto ${ }^{2}$, A. Pavilonis ${ }^{1}$, I. Klimiene ${ }^{1}$, R. Siugzdiniene ${ }^{1}$, \\ M. Virgailis ${ }^{1}$, L. Vaskeviciute ${ }^{1}$, L. Anskiene ${ }^{3}$, C. Pomba ${ }^{2}$ \\ ${ }^{1}$ Institute of Microbiology and Virology, Lithuanian University of Health Sciences, \\ Tilzes g. 18, Kaunas, Lithuania \\ ${ }^{2}$ Faculdade de Medicina Veterinaria, Universidade de Lisboa, \\ Avenida da Universidade Tecnica, 1300-477, Lisboa, Portugal \\ ${ }^{3}$ Department of Animal Reproduction, Lithuanian University of Health Sciences, \\ Tilzes g. 18, Kaunas, Lithuania
}

\begin{abstract}
The aim of this study was to characterize Staphylococcus pseudintermedius for its antimicrobial resistance and virulence factors with a special focus on methicillin-resistant (MRSP) strains isolated from sick dogs in Lithuania. Clinically sick adult dogs suffering from infections $(n=214)$ and bitches with reproductive disorders $(n=36)$ from kennels were selected for the study. Samples $(n=192)$ from the 250 tested $(76.8 \%)$ dogs were positive for Staphylococcus spp. Molecular profiling using the species-specific nuc gene identified 51 isolates as $S$. pseudintermedius (26.6\% from a total number of isolated staphylococci) of which 15 isolates were identified as MRSP. Ten MRSP isolates were isolated from bitches with reproductive disorders from two large breeding kennels. Data on susceptibility of $S$. pseudintermedius to different antimicrobials revealed that all isolates were susceptible to vancomycin, daptomycin and linezolid. Two isolates $(3.9 \%)$ were resistant to rifampicin. A high resistance was seen towards penicillin $\mathrm{G}(94.1 \%)$, tetracycline $(64.7 \%)$ and macrolides $(68.7 \%)$. Resistance to fluoroquinolones ranged from $25.5 \%$ (gatifloxacin) to $31.4 \%$ (ciprofloxacin). The most prevalent genes encoding resistance included blaZ, aac(6')-Ie-aph(2')-Ia, mecA, and tet(M). The Luk-I gene encoding a leukotoxin was detected in $29 \%$ of the isolates, whereas the siet gene encoding exfoliative toxin was detected in $69 \%$ of the $S$. pseudintermedius isolates. This report of MRSP in companion animals represents a major challenge for veterinarians in terms of antibiotic therapy and is a concern for both animal and public health.
\end{abstract}

Key words: MRSP, companion animals, resistance, antimicrobials, toxins

Correspondence to: M. Ruzauskas, e-mail: modestas.ruzauskas@1smuni.lt 


\section{Introduction}

Staphylococcus pseudintermedius is an important opportunistic pathogen of companion animals, especially dogs (van Duijkeren et al. 2011). Canine infections caused by $S$. pseudintermedius are mostly skin infections, endometritis, cystitis and other less frequent infections (Cox et al. 1984, Morris et al. 2006). $S$. pseudintermedius has various virulence factors, including some that are closely related to the virulence factors of $S$. aureus (Futagawa-Saito et al. 2004b, Fitzgerald 2009). It produces enzymes such as coagulase, protease, thermonuclease and toxins, including haemolysins and exfoliative toxins (Fitzgerald 2009, Ben Zakour 2011). S. pseudintermedius also produces a leucotoxin known as Luk-I, which is very similar to Panton-Valentine leucocidin (PVL) from $S$. aureus (Futagawa-Saito et al. 2009, Futagawa Saito et al. 2004a).

Methicillin-resistant $S$. pseudintermedius (MRSP) has posed an increasing therapeutic challenge because of its limited treatment options. Colonization and infection caused by MRSP has been described in dogs, cats, horses, birds and humans. This fact demonstrates the zoonotical potential of $S$. pseudintermedius. It is also known that dogs can carry the same or similar MRSP strains for months without active infection. Several reports on isolates not susceptible to any antimicrobials authorized for use in veterinary medicine have been published causing veterinarians to consider using antimicrobials authorized for human medicine only. Good veterinary practice requires the use of antimicrobial treatment after correct diagnosis and susceptibility testing. However, reliable commercial identification systems for fast and correct identification of S. pseudintermedius are not currently available. In many cases, isolates will be erroneously identified as $S$. intermedius or $S$. aureus.

MRSP isolates are characterized by the presence of the mec $A$ gene, which is located on staphylococcal cassette chromosome mec (SCCmec) elements and confers resistance to all f-lactam antibiotics. In addition to $m e c A$, MRSP also may contain a wide range of antibiotic resistance genes. In addition to $\beta$-lactam resistance, resistance to 11 other antimicrobials was observed in a study of 103 epidemiologically unrelated MRSP isolates from dogs from Canada, the USA, Denmark, Germany, France, Italy, Sweden, Switzerland and the Netherlands. The resistance of S. pseudintermedius depends on geographical distribution as well as on other factors - thus, it is important to obtain data from different countries to better understand the epidemiological spread of resistance.

The aim of this study was to characterize Staphylococcus pseudintermedius in sick Lithuanian dogs for antimicrobial resistance and virulence factors with a special focus on methicillin-resistant (MRSP) strains.

\section{Materials and Methods}

The investigations were carried out at the Lithuanian University of Health Sciences, Institute of Microbiology and Virology.

\section{Sample collection}

Two hundred and fifty dogs were randomly selected from small animal clinics located throughout the country as well as in breeding kennels of pure-breed dogs. Clinically sick adult dogs suffering from skin infections $(n=155)$, otitis $(n=48)$, respiratory tract infections $(n=11)$ and bitches with reproductive disorders (metritis, temporal infertility, premature birth) $(n=36)$ were selected for the study. The age ranged between 2 and 8 years. Anamnesis data showed that 190 dogs were untreated with antimicrobials at least 6 months before sampling; 45 sick dogs were treated over different intervals during the last 0-30 days before sampling. Fifteen bitches in kennels were prophylactically treated with fluoroquinolones and/or cephalosporins during the previous 3 months. Sterile cotton swabs with transport media (TRANSWAB, Polysciences Inc.) or sterile syringes were used for collection of clinical samples. These samples were delivered to the laboratory on the same day. Only one sample from the affected organ was taken from each dog.

\section{Bacteriological testing and DNA extraction}

Samples were inoculated onto Mannitol-Salt Agar (Liofilchem, Italy) and Mannitol-Salt Agar supplemented with oxacillin (Sigma-Aldrich). Suspected colonies of Staphylococcus spp. were tested for presumptive genus identification according to the production of haemolysis, catalase, gram-staining, susceptibility to furazolidone, morphology and growing characteristics followed by a latex agglutination test („Staph Latex Kit”, Microgen, UK). Presumptive S. pseudintermedius isolates were identified up to species level using the RapID STAPH PLUS (Thermo Scientific) identification system and ERIC ${ }^{\circledR}$ manufacturer's software.

DNA material for molecular testing was obtained after bacterial lysis according to the extraction protocol prepared by the Community Reference Labora- 
Table 1. Oligonucleotide primers used in this study.

\begin{tabular}{|c|c|c|c|c|}
\hline $\begin{array}{l}\text { Primer } \\
\text { name }\end{array}$ & Sequence $\left(5^{\prime}-3^{\prime}\right)$ & $\begin{array}{l}\text { Size, bp } \\
\text { and } \mathrm{T}\left({ }^{\circ} \mathrm{C}\right)\end{array}$ & Target gene & Source \\
\hline $\begin{array}{l}\text { nuc1 } \\
\text { nuc2 }\end{array}$ & $\begin{array}{l}\text { TRGGCAGTAGGATTCGTTAA } \\
\text { CTTTTGTGCTYCMTTTTGG }\end{array}$ & $926(58)$ & nuс & Sasaki et al. 2010 \\
\hline $\begin{array}{l}\text { siet1 } \\
\text { siet2 }\end{array}$ & $\begin{array}{l}\text { ATGGAAAATTTAGCGGCATCTGG } \\
\text { CCATTACTTTTCGCTTGTTGTGC }\end{array}$ & $359(56)$ & exfoliative toxin & Lautz et al. 2006 \\
\hline $\begin{array}{l}\text { lukS1 } \\
\text { lukS2 }\end{array}$ & $\begin{array}{l}\text { TGTAAGCAGCAGAAAATGGGG } \\
\text { GCCCGATAGGACTTCTTACAA }\end{array}$ & $503(57)$ & $l u k \mathrm{~S}$ & Futagawa-Saito et al. 2004-1 \\
\hline $\begin{array}{l}\text { lukF1 } \\
\text { lukF2 }\end{array}$ & $\begin{array}{l}\text { CCTGTCTATGCCGCTAATCAA } \\
\text { AGGTCATGGAAGCTATCTCGA }\end{array}$ & $572(57)$ & $l u k \mathrm{~F}$ & Futagawa-Saito et al. 2004-1 \\
\hline $\begin{array}{l}\operatorname{mec} A 1 \\
\operatorname{mec} A 2\end{array}$ & $\begin{array}{l}\text { GGGATCATAGCGTCATTATTC } \\
\text { AACGATTGTGACACGATAGCC }\end{array}$ & $527(61)$ & mecA & Poulsen et al. 2003 \\
\hline $\begin{array}{l}\operatorname{mecC} 1 \\
\operatorname{mecC} 2\end{array}$ & $\begin{array}{l}\text { GCTCCTAATGCTAATGCA } \\
\text { TAAGCAATAATGACTACC }\end{array}$ & $204(50)$ & $m e c \mathrm{C}$ & Cuny et al. 2011 \\
\hline $\begin{array}{l}\text { blaZ1 } \\
\text { blaZ2 }\end{array}$ & $\begin{array}{l}\text { CAGTTCACATGCCAAAGAG } \\
\text { TACACTCTTGGCGGTTTC }\end{array}$ & $772(50)$ & blaZ & Schnellmann et al. 2006 \\
\hline $\begin{array}{l}\text { tetM1 } \\
\text { tetM2 }\end{array}$ & $\begin{array}{l}\text { GTTAAATAGTGTTCTTGGAG } \\
\text { CTAAGATATGGCTCTAACAA }\end{array}$ & $656(45)$ & tet $\mathrm{M}$ & Aarestrup et al. 2000 \\
\hline $\begin{array}{l}\text { tetK1 } \\
\text { tetK2 }\end{array}$ & $\begin{array}{l}\text { TTAGGTGAAGGGTTAGGTCC } \\
\text { GCAAACTCATTCCAGAAGCA }\end{array}$ & $718(55)$ & tet $\mathrm{K}$ & Aarestrup et al. 2000 \\
\hline $\begin{array}{l}\text { aac6-aph2F } \\
\text { aac6-aph2R }\end{array}$ & $\begin{array}{l}\text { CAGAGCCTTGGGAAGATGAAG } \\
\text { CCTCGTGTAATTCATGTTCTGGC }\end{array}$ & $348(61)$ & $\operatorname{aac}\left(6^{\prime}\right)-I e-a p h\left(2^{\prime \prime}\right)-I a$ & Perreten et al. 2005 \\
\hline $\begin{array}{l}\text { aph3-IIF } \\
\text { aph3-IIR }\end{array}$ & $\begin{array}{l}\text { CCGCTGCGTAAAAGATAC } \\
\text { GTCATACCACTTGTCCGC }\end{array}$ & $609(57)$ & $\operatorname{aph}\left(3^{\prime}\right)-I I I a$ & Perreten et al. 2005 \\
\hline $\begin{array}{l}\text { dfrK1 } \\
\text { dfrK2 }\end{array}$ & $\begin{array}{l}\text { GCTGCGATGGATAAGAACAG } \\
\text { GGACGATTTCACAACCATTAAAGC }\end{array}$ & $214(50)$ & dfrK & Kadlec and Schwarz 2010 \\
\hline $\begin{array}{l}\text { ermA1 } \\
\text { ermA2 }\end{array}$ & $\begin{array}{l}\text { AAGCGGTAAAACCCCTCTGAG } \\
\text { TCAAAGCCTGTCGGAATTGG }\end{array}$ & $442(53)$ & erm $\mathrm{A}$ & Jensen et al. 2002 \\
\hline $\begin{array}{l}\text { ermC1 } \\
\text { ermC2 }\end{array}$ & $\begin{array}{l}\text { ATCTTTGAAATCGGCTCAGG } \\
\text { CAAACCCGTATTCCACGATT }\end{array}$ & $295(48)$ & erm $\mathrm{C}$ & Jensen et al. 2002 \\
\hline $\begin{array}{l}\text { ermB1 } \\
\text { ermB2 }\end{array}$ & $\begin{array}{l}\text { GGAACATCTGTGGTATGGCG } \\
\text { CATTTAACGACGAAACTGGC }\end{array}$ & $425(48)$ & ermB & Jensen et al. 2002 \\
\hline $\begin{array}{l}\operatorname{msrA} 1 \\
\operatorname{msrA} 2\end{array}$ & $\begin{array}{l}\text { GCTTAACATGGATGTGG } \\
\text { GATTGTCCTGTTAATTCCC }\end{array}$ & $1230(55)$ & $m s r \mathrm{~A}$ & Perreten et al. 2005 \\
\hline $\begin{array}{l}16 \mathrm{~S} 1 \\
16 \mathrm{~S} 2\end{array}$ & $\begin{array}{l}\text { GTGCCAGCAGCCGCGGTAA } \\
\text { AGACCCGGGAACGTATTCAC }\end{array}$ & $886(61)$ & $16 S$ staph & Poulsen et al. 2003 \\
\hline
\end{tabular}

tory for Antimicrobial Resistance with slight modifications. Briefly, bacterial colonies were taken with a bacteriological loop from the surface of Mueller Hinton Agar and transferred to phosphate buffered saline ( $\mathrm{pH}$ 7.3). The content was centrifuged for $5 \mathrm{~min}$. The supernatant was then discarded and the pellet was re-suspended in Tris-EDTA (TE) buffer. The suspension was heated using a Biosan (Latvia) thermomixer to $100^{\circ} \mathrm{C}$ degrees for 10 minutes. The boiled suspension was transferred directly onto ice and diluted by 1:10 in TE.

\section{Molecular testing}

The species-specific thermonuclease (nuc) gene for $S$. pseudintermedius as well as the $16 \mathrm{~S}$ rRNR gene was tested by PCR using oligonucleotides described previously (Poulsen et al. 2003, Sasaki et al. 2010). The positive control strain for $S$. pseudintermedius (previously confirmed by sequencing analysis of the $16 \mathrm{~S}$ rRNA gene) was obtained from the Laboratory of Antimicrobial and Biocide Resistance, Technical University of Lisbon. Oligonucleotides used for detection 
of antimicrobial resistance and virulence genes are presented in Table 1.

\section{Antimicrobial susceptibility}

Antimicrobial susceptibility testing was performed using the broth microdilution method. Sensititre plates and the ARIS 2X automated system (Thermo Scientific) were used with the following antimicrobials: ceftriaxone, daptomycin, gatifloxacin, ciprofloxacin, clindamycin, erythromycin, gentamicin, levofloxacin, linezolid, oxacillin, penicillin, quinupristin/dalfopristin and rifampicin. Interpretation of results was carried out using the manufacturer's software $\left(\mathrm{SWIN}^{\circledR}\right)$ adapted to clinical breakpoints of the Clinical and Laboratory Standards Institute (CLSI). The quality control strain $S$. aureus ATCC 29213 was included in each assay for validation purposes.

\section{PCR assays for antimicrobial and virulence genes}

Detection of genes encoding antimicrobial resistance $(\operatorname{mec} A, \operatorname{mec} C, b l a Z, \operatorname{tet}(\mathrm{K}), \operatorname{tet}(\mathrm{M}), \operatorname{erm}(\mathrm{A})$, $\operatorname{erm}(\mathrm{C}), m s r \mathrm{~A} / \mathrm{B}, a a c\left(6^{\prime}\right)-I e-a p h\left(2^{\prime \prime}\right)-I a, a p h\left(3^{\prime}\right)-I I I a$ and $d f r K)$ was performed. Isolates were also tested for the lukF/lukS genes encoding leukocidin Luk-I and for the siet gene encoding exfoliative toxin. Annealing temperatures and oligonucleotides used are presented in Table 1. Positive control strains (previously confirmed by sequencing analysis) were obtained from the Laboratory of Antimicrobial and Biocide Resistance, Technical University of Lisbon.

\section{Statistical analysis}

Statistical analysis was performed using the „R 1.8.1" package (http://www.r-project.org/). Comparison between categorical variables was calculated using the chi-square test and Fisher's exact test. Results were considered statistically significant if $\mathrm{p}<0.05$.

\section{Results}

One hundred and ninety two samples from 250 tested $(76.8 \%)$ were positive for the presence of Staphylococcus species. The percentage was higher in non-treated animals $(89.5 \%)$. Fifty-four isolates did not ferment mannitol on mannitol-salt agar, had a positive reaction with Microgen Staph Latex Kit and expressed a large double zone of haemolysis on sheep-blood agar. Thirty-two isolates were initially identified as $S$. intermedius using a biochemical identification system. Molecular typing using the species-specific nuc gene identified 51 isolates as $S$. pseudintermedius $(26.6 \%)$ including those previously identified as S. intermedius. Fifteen samples $(29.4 \%)$ from different dogs were able to grow on mannitol salt agar supplemented with $2 \mathrm{mg} / \mathrm{L}$ oxacillin. The $m e c A$ gene was detected in all of these isolates, all of them being resistant to oxacillin and identified as MRSP. The mec $\mathrm{C}$ gene was not detected. Ten MRSP isolates were isolated in two kennels (previously treated with fluoroquinolones and/or cephalosporins) breeding Yorkshire terriers, French Bulldogs and English Bulldogs (number of adult dogs in each kennel was 18 and 22 respectively).

Table 2 presents data on the distribution of $S$. pseudintermedius including MRSP isolates in dogs with different clinical infections, together with the number of isolates harbouring genes encoding production of Luk-I and siet.

The data presented in Table 2 demonstrate that $S$. pseudintermedius was isolated from dogs with different clinical infections, although the highest frequency of this species was detected in dogs with pyoderma. Ten MRSP isolates were isolated in two large breeding kennels from bitches with reproductive disorders.

Genes encoding production of Luk-I toxin were not associated with any of the clinical infections ( $>0.5)$; however, the siet gene, responsible for the production of an exfoliative toxin, was significantly associated with isolates from skin infections $(\mathrm{p}<0.01)$. From all isolates, $68.6 \%$ had at least one gene responsible for the production of toxins.

Data on antimicrobial susceptibility of the isolates is presented in Table 3.

All $S$. pseudintermedius isolated strains were susceptible to vancomycin, daptomycin and linezolid. Two isolates $(3.9 \%)$ were resistant to rifampicin. More frequent resistance was demonstrated to penicillin $(94.1 \%)$, tetracycline $(64.7 \%)$ and macrolides $(68.7 \%)$. Resistance to fluoroquinolones was high and ranged from $25.5 \%$ (gatifloxacin) to $31.4 \%$ (ciprofloxacin). Genes encoding resistance to separate classes of antimicrobials were found in different numbers (Table 3 ). The most prevalent genes included blaZ, aac(6')-Ie-aph(2")-Ia, mecA, and tet(M).

\section{Discussion}

Bacteria of the genus Staphylococcus are highly prevalent in clinical samples from small animals. In general, we found that $76.8 \%$ of the tested samples were positive although the prevalence was higher in 
Table 2. Clinical infections associated with $S$. pseudintermedius including MRSP and presence of the genes encoding toxins.

\begin{tabular}{|c|c|c|c|c|c|c|}
\hline \multirow[b]{2}{*}{ Clinical disorder } & \multirow{2}{*}{$\begin{array}{c}\text { Number of } \\
\text { pseudintermedius } \\
\text { lates }\end{array}$} & & \multirow{2}{*}{$\begin{array}{c}\text { Number of MRSP } \\
\text { isolates }\end{array}$} & \multicolumn{3}{|c|}{ Genes encoding toxins } \\
\hline & & iso- & & $\operatorname{lukS}$ & $\operatorname{luk\mathrm {F}}$ & siet \\
\hline Otitis & 5 & & 0 & 2 & 2 & 3 \\
\hline Pyoderma & 24 & & 4 & 6 & 6 & 22 \\
\hline Reproductive disorders & 18 & & 10 & 6 & 6 & 9 \\
\hline Other & 4 & & 1 & 1 & 1 & 1 \\
\hline
\end{tabular}

Table 3. Antimicrobial susceptibility data and genes encoding resistance in $S$. pseudintermedius isolates $(\mathrm{n}=51)$.

\begin{tabular}{|c|c|c|c|c|c|}
\hline \multirow{2}{*}{ Class of antimicrobials } & \multirow{2}{*}{ Antimicrobial } & \multicolumn{3}{|c|}{ Susceptibility $^{1}, \mathrm{n}(\%)$} & \multirow{2}{*}{$\begin{array}{l}\text { Genes encoding } \\
\text { resistance }\end{array}$} \\
\hline & & $\mathrm{S}$ & I & $\mathrm{R}$ & \\
\hline \multirow{2}{*}{ Penicillins } & Penicillin & $3(5.9)$ & - & $48(94.1)$ & \multirow{3}{*}{$\begin{array}{l}\operatorname{bla} \mathrm{Z}(45)^{3} \\
\operatorname{mec} \mathrm{A}(15)\end{array}$} \\
\hline & Oxacillin & $36(70.6)$ & - & $15(29.4)$ & \\
\hline Cephalosporins & Ceftriaxone & $35(68.6)$ & $3(5.9)$ & $13(25.5)$ & \\
\hline Tetracyclines & Tetracycline & $18(35.3)$ & - & $33(64.7)$ & $\begin{array}{c}\operatorname{tet}(\mathrm{K})(6) \\
\operatorname{tet}(\mathrm{M})(14)\end{array}$ \\
\hline \multirow{3}{*}{$\begin{array}{l}\text { Macrolides, lincosamides } \\
\text { and streptogramins }\end{array}$} & Erythromycin & $14(27.5)$ & $1(2.0)$ & $36(70.6)$ & $\operatorname{erm}(\mathrm{A})(1)$ \\
\hline & Clindamycin & $14(27.5)$ & - & $37(72.5)$ & $\operatorname{erm}(\mathrm{C})(3)$ \\
\hline & Quinupristin/dalfopristin & $48(94.1)$ & $2(3.9)$ & $1(2.0)$ & $m s r A / B(6)$ \\
\hline \multirow[t]{2}{*}{ DFR inhibitors } & Trimethoprim & $36(70.6)$ & - & $15(29.4)$ & $d f r K(8)$ \\
\hline & Ciprofloxacin & $35(68.7)$ & - & $16(31.4)$ & $\mathrm{nt}$ \\
\hline \multirow[t]{2}{*}{ Fluoroquinolones } & Gatifloxacin & $38(74.5)$ & - & $13(25.5)$ & $\mathrm{nt}$ \\
\hline & Levofloxacin & $36(70.6)$ & $1(2.0)$ & $14(27.5)$ & $\mathrm{nt}$ \\
\hline Rifamycins & Rifampicin & $49(96.1)$ & - & $2(3.9)$ & $\mathrm{nt}$ \\
\hline Lipopeptides & Daptomycin & $51(100)$ & - & $0(0)$ & $\mathrm{nt}$ \\
\hline Glycopeptides & Vancomycin & $51(100)$ & - & $0(0)$ & $\mathrm{nt}$ \\
\hline Aminoglycosides & Gentamicin & $25(49.0)$ & $7(13.7)$ & $19(37.6)$ & $\begin{array}{c}a a c\left(6^{\prime}\right)-I e-\operatorname{aph}\left(2^{\prime \prime}\right)-I a(16) \\
\operatorname{aph}\left(3^{\prime}\right)-I I I a(11)\end{array}$ \\
\hline Oxazolidinones & Linezolid & $51(100)$ & - & $0(0)$ & $\mathrm{nt}$ \\
\hline
\end{tabular}

${ }^{1} \mathrm{~S}$ - susceptible; I - intermediate susceptible; R - resistant

${ }^{2} \mathrm{nt}-$ not tested

${ }^{3}$ in parentheses - number of isolates harbouring the tested genes

non-treated animals $(89.5 \%)$. Such data are consistent with data obtained by other authors (Griffeth 2008, Penna et al. 2010). We focused on S. pseudintermedius since it is the most prevalent species in dogs (Hauschild and Wójcik 2007, Penna et al. 2010, Bannoehr and Guardabassi 2012). Moreover, S. pseudintermedius is often reported as methicillin-resistant with co-resistance to different classes of antimicrobials other than beta-lactams (Perreten et al. 2010, Weese and Duijkeren 2010, Windahl et al. 2012). The number of $S$. pseudintermedius isolates $(26.6 \%)$ revealed that this species is widely distributed in clinical samples from dogs although there are other species that are prevalent as well (data not presented).

There are different data about the prevalence of $S$. pseudintermedius described by other authors. For example, Feng et al. (2012) reported a prevalence of $18.3 \%$, while Garbacz et al. (2013) described it to be $51.8 .4 \%$ of tested animals. Data on the prevalence might depend on study design, identification methods, sampling, animal health status and other factors. It is known that classical biochemical tests for species identification are not always capable of identifying $S$. pseudintermedius (van Duijkeren et al. 2011). We found this to be true as well. Certain substrates (carbohydrates and amino acids) are weakly fermented and thus interpretation of results based on a colour index is subjective.

In our study $S$. pseudintermedius was isolated from dogs with different clinical infections, and thus we detected genes encoding for pathogenicity factors. We detected a high frequency $(68.8 \%)$ of luk and/or siet 
genes in S. pseudintermedius isolates in Lithuania. Interestingly, all isolates that harboured both $l u k F$ and lukS genes harboured the siet gene as well $(\mathrm{p}<0.01)$ but not vice versa. To our knowledge such a statistical relationship had not been detected before. Statistically reliable results were obtained when studying the association between the presence of siet gene in isolates from skin infections compared with isolates obtained from other types of infection. This agrees with the fact that the exfoliative toxin is a virulence factor of $S$. pseudintermedius involved in canine pyoderma. It is mainly found among isolates from skin infections (Lautz et al. 2006, Iyori et al. 2010). The luk genes were found in different $S$. pseudintermedius strains irrespective of the source of isolation. The Luk-I shows strong leucotoxicity towards various polymorphonuclear cells (Futagawa et al. 2004a). It might be responsible for invasion of the host by suppressing its cellular immunity and could be produced by different strains of $S$. pseudintermedius.

Data on antimicrobial susceptibility revealed that $S$. pseudintermedius most frequently has resistance to antimicrobials used in dogs including penicillins (resistance attributed to blaZ gene), tetracyclines $(\operatorname{tet}(\mathrm{K})$ and $\operatorname{tet}(\mathrm{M})$ genes) and macrolides (erm $\mathrm{A}$ and $\operatorname{erm} \mathrm{C}$ genes).

The erm $\mathrm{B}$ gene was not detected. In fact, this gene is rarely isolated (1.9\%) in MRSP isolates from Europe and North America collected previously (Perreten et al. 2010), except in Norway where resistance of $S$. pseudintermedius was attributed to the erm $\mathrm{B}$ gene (Norstrom et al. 2009). A high rate of resistance to fluoroquinolones (25.5-31.4\%) was also recorded. Resistance mechanisms to fluoroquinolones of $S$. pseudintermedius are well described (Descloux et al. 2008). The high frequency of resistance to fluoroquinolones found here could be explained in that fluoroquinolones are frequently used to treat dog infections especially in cases with unsatisfactory clinical practice where broad-spectrum antimicrobials are selected for treatment without sending clinical material to a laboratory for diagnosis and antibiogram. Resistance of $S$. pseudintermedius isolates to gentamicin was also high (37.6\%). The genes responsible for encoding resistance to aminoglycosides $a a c\left(6^{\prime}\right)-I e-a p h\left(2^{\prime \prime}\right)-I a$ and $a p h\left(3^{\prime}\right)-I I I a$ were detected here. The same genes were recently found in most isolates of enterococci isolated from diseased cows, pigs and poultry in Lithuania (Seputiene et al. 2012). Those genes encoding resistance to aminoglycosides were also found in S. pseudintermedius in other countries (Kadlec et al. 2010). It is interesting that resistant isolates to gentamicin harboured the siet gene as a rule $(\mathrm{p}<0.01)$.
In this study, 29.4\% of S. pseudintermedius strains were identified as MRSP. Lithuania-specific data on methicillin resistant staphylococci isolated from animals is scarce - the first case of methicillin resistance in livestock was only reported in 2011, when MRSA ST398 strains were found and characterised in pigs (Ruzauskas et al. 2013). To the best of our knowledge, this study is the first Lithuanian study where MRSP strains were confirmed using molecular methods. This high frequency of MRSP in dogs could be explained as follows: first, only diseased animals were involved in the study and most of them were being treated or had been treated previously with an antimicrobial. Second, as proven before, the use of fluoroquinolones and cephalosporins might select for antimicrobial resistant bacteria (SAGAM 2009, van Duijkeren et al. 2011) and some of these dogs had been previously treated with some of these antimicrobial drugs. Finally, 10 MRSP isolates were isolated on two large breeding kennels from bitches with reproductive disorders in which the owners irregularly used antimicrobials, including enrofloxacin and/or cefovecin for "better reproductive performance". Such inappropriate use of antimicrobials possibly led to high resistance rates of MRSP in these kennels. Thus, breeding kennels might be a reservoir of MRSP strains and may pose a risk for spreading such strains during mating. There is no requirement for reporting MRSP or MRSA strains prevalent in kennels. Thus, other breeders have no information about the status of such animals. Attention should be paid to this problem since methicillin-resistant staphylococci pose a risk not only to animals but also to humans (Catry et al. 2010, Stegmann et al. 2010, van Duijkeren et al. 2011).

Our findings indicate that staphylococci including $S$. pseudintermedius are very common in clinical samples from diseased dogs. The prevalence of genes encoding toxins in $S$. pseudintermedius is high as also the resistance rates to some critically important antimicrobials such as beta-lactams and fluoroquinolones. Isolates remain susceptible only to those antimicrobials that are still banned from veterinary use (linezolid, vancomycin, and daptomycin). Such antibiotics should be reserved for humans and control of their use in kennels needs to be improved. Monitoring of antimicrobial resistance in kennels should be performed routinely and should include control options to avoid the spread of resistance.

\section{Acknowledgements}

This research was funded by grants (MIP-075/2013 and SIT-6/2015) from the Research Council of Lithuania. 


\section{References}

Aarestrup FM, Agerso Y, Gerner-Smidt P, Madsen M, Jensen LB (2000) Comparison of antimicrobial resistance phenotypes and resistance genes in Enterococcus faecalis and Enterococcus faecium from humans in the community, broilers, and pigs in Denmark. Diagn Microbiol Infect Dis 37: 127-137.

Bannoehr J, Guardabassi L (2012) Staphylococcus pseudintermedius in the dog: taxonomy, diagnostics, ecology, epidemiology and pathogenicity. Vet Dermatol 23: 253-266.

Ben Zakour NL, Bannoehr J, van den Broek AH, Thoday KL, Fitzgerald JR (2011) Complete genome sequence of the canine pathogen Staphylococcus pseudintermedius. J Bacteriol 193: 2363-2364.

Catry B, van Duijkeren E, Pomba MC, Greco C, Moreno MA, Pyörälä S, Ruzauskas M, Sanders P, Threlfall EJ, Ungemach $\mathrm{F}$, Törneke $\mathrm{K}$, Munoz-Madeiro $\mathrm{C}$, Torren-Edo J (2010) Reflection paper on MRSA in food producing and companion animals: epidemiology and control options for human and animal health. Epidemiol Infect 138: 626-644.

Couto N, Pomba C, Moodley A, Guardabassi L (2011) Prevalence of meticillin-resistant staphylococci among dogs and cats at a veterinary teaching hospital in Portugal. Vet Rec 169: 72.

Cox HU, Newman SS, Roy AF, Hoskins JD (1984) Species of Staphylococcus isolated from animal infections. Cornell Vet 74: 124-135.

Cuny C, Layer F, Strommenger B, Witte W (2011) Rare occurrence of methicillin-resistant Staphylococcus aureus CC130 with a novel $m e c A$ homologue in humans in Germany. PloS One 6: e24360.

Descloux S, Rossano A, Perreten V (2008) Characterization of new staphylococcal cassette chromosome mec (SCCmec) and topoisomerase genes in fluoroquinoloneand methicillin-resistant Staphylococcus pseudintermedius. J Clin Microbiol 46: 1818-1823.

Feng Y, Tian W, Lin D, Luo Q, Zhou Y, Yang T, Deng Y, Liu YH, Liu JH (2012) Prevalence and characterization of methicillin-resistant Staphylococcus pseudintermedius in pets from South China. Vet Microbiol 160: 517-524.

Fitzgerald JR (2009) The Staphylococcus intermedius group of bacterial pathogens: species re-classification, pathogenesis and the emergence of methicillin resistance. Vet Dermatol 20: 490-495.

Futagawa-Saito K, Makino S, Sunaga F, Kato Y, Sakurai-Komada N, Ba-Thein W, Fukuyasu T (2009) Identification of first exfoliative toxin in Staphylococcus pseudintermedius. FEMS Microbiol Lett 301: 176-180.

Futagawa-Saito K, Sugiyama T, Karube S, Sakurai N, Ba-Thein W, Fukuyasu T (2004a) Prevalence and characterization of leukotoxin-producing Staphylococcus intermedius in isolates from dogs and pigeons. J Clin Microbiol 42: 5324-5326.

Futagawa-Saito K, Suzuki M, Ohsawa M, Ohshima S, Sakurai N, Ba-Thein W, Fukuyasu T (2004b) Identification and prevalence of an enterotoxin-related gene, se-int, in Staphylococcus intermedius isolates from dogs and pigeons. J Appl Microbiol 96: 1361-1366.

Garbacz K, Ćarnowska S, Piechowicz L, Haras K (2013) Pathogenicity potential of Staphylococcus pseudinter- medius strains isolated from canine carriers and from dogs with infection signs. Virulence 4: 255-259.

Griffeth GC, Morris DO, Abraham JL, Shofer FS, Rankin SC (2008) Screening for skin carriage of methicillin-resistant coagulase-positive staphylococci and Staphylococcus schleiferi in dogs with healthy and inflamed skin. Vet Dermatol 19: 142-149.

Hauschild T, Wójcik A (2007) Species distribution and properties of taphylococci from canine dermatitis. Res Vet Sci 82: 1-6.

Iyori K, Hisatsune J, Kawakami T, Shibata S, Murayama N, Ide K, Nagata M, Fukata T, Iwasaki T, Oshima K, Hattori M, Sugai M, Nishifuji K (2010) Identification of a novel Staphylococcus pseudintermedius exfoliative toxin gene and its prevalence in isolates from canines with pyoderma and healthy dogs. FEMS Microbiol Lett 312: 169-175.

Jensen LB, Hammerum AM, Bager F, Aarestrup FM (2002) Streptogramin resistance among Enterococcus faecium isolated from production animals in Denmark in 1997. Microb Drug Resist 8: 369-374.

Kadlec K, Schwarz S (2010) Identification of the novel $d$ frK-carrying transposon Tn559 in a porcine methicillin-susceptible Staphylococcus aureus ST398 strain. Antimicrob Agents Chemother 54: 3475-3477.

Kadlec K, Schwarz S, Perreten V, Andersson UG, Finn M, Greko C, Moodley A, Kania SA, Frank LA, Bemis DA, Franco A, Iurescia M, Battisti A, Duim B, Wagenaar JA, van Duijkeren E, Weese JS, Fitzgerald JR, Rossano A, Guardabassi L (2010) Molecular analysis of methicillin-resistant Staphylococcus pseudintermedius of feline origin from different European countries and North America. J Antimicrob Chemother 65: 1826-1828.

Lautz S, Kanbar T, Alber J, Lämmler C, Weiss R, Prenger-Berninghoff E, Zschöck M (2006) Dissemination of the gene encoding exfoliative toxin of Staphylococcus intermedius among strains isolated from dogs during routine microbiological diagnostics. J Vet Med B Infect Dis Vet Public Health 53: 434-438.

Loeffler A, Linek M, Moodley A, Guardabassi L, Sung JM, Winkler M, Weiss R, Lloyd DH (2007) First report of multiresistant, mecA-positive Staphylococcus intermedius in Europe: 12 cases from a veterinary dermatology referral clinic in Germany. Vet Dermatol 18: 412-421.

Morris DO, Rook KA, Shofer FS, Rankin SC (2006) Screening of Staphylococcus aureus, Staphylococcus intermedius, and Staphylococcus schleiferi isolates obtained from small companion animals for antimicrobial resistance: a retrospective review of 749 isolates $(2003-04)$. Vet Dermatol 17: 332-337.

Norström M, Sunde M, Tharaldsen H, Mørk T, Bergsjø B, Kruse H (2009) Antimicrobial resistance in Staphylococcus pseudintermedius in the Norwegian dog population. Microb Drug Resist 15: 55-59.

Penna B, Varges R, Medeiros L, Martins GM, Martins RR, Lilenbaum W (2010) Species distribution and antimicrobial susceptibility of staphylococci isolated from canine otitis externa. Vet Dermatol 21: 292-296.

Perreten V, Kadlec K, Schwarz S, Grönlund Andersson U, Finn M, Greko C, Moodley A, Kania SA, Frank LA, Bemis DA, Franco A, Iurescia M, Battisti A, Duim B, Wagenaar JA, van Duijkeren E, Weese JS, Fitzgerald JR, Rossano A, Guardabassi L (2010) Clonal spread of methicillin-resistant Staphylococcus pseudintermedius 
in Europe and North America: an international multicentre study. J Antimicrob Chemother 65: 1145-1154.

Perreten V, Vorlet-Fawer L, Slickers P, Ehricht R, Kuhnert P, Frey J (2005) Microarray-based detection of 90 antibiotic resistance genes of gram-positive bacteria. $\mathrm{J}$ Clin Microbiol 43: 2291-2302.

Pomba C, Couto N, Moodley A (2010) Treatment of a lower urinary tract infection in a cat caused by a multi-drug methicillin-resistant Staphylococcus pseudintermedius and Enterococcus faecalis. J Feline Med Surg 12: 802-806.

Poulsen AB, Skov R, Pallesen LV (2003) Detection of methicillin resistance in coagulase-negative staphylococci and in staphylococci directly from simulated blood cultures using the EVIGENE MRSA Detection Kit. J Antimicrob Chemother 51: 419-421.

Ruscher C, Lübke-Becker A, Semmler T, Wleklinski CG, Paasch A, Soba A, Stamm I, Kopp P, Wieler LH, Walther B (2010) Widespread rapid emergence of a distinct methicillin- and multidrug-resistant Staphylococcus pseudintermedius (MRSP) genetic lineage in Europe. Vet Microbiol 144: 340-346.

Ruscher C, Lübke-Becker A, Wleklinski CG, Soba A, Wieler LH, Walther B (2008) Prevalence of methicillin-resistant Staphylococcus pseudintermedius isolated from clinical samples of companion animals and equidaes. Vet Microbiol 136: 197-201.

Ruzauskas M, Couto N, Belas A, Klimiene I, Siugzdiniene R, Pomba C (2013) First report of swine-associated methicillin-resistant Staphylococcus aureus ST398 in Lithuania. Pol J Vet Sci 16: 125-127.

Sasaki T, Tsubakishita S, Tanaka Y, Sakusabe A, Ohtsuka M, Hirotaki S, Kawakami T, Fukata T, Hiramatsu K (2010) Multiplex-PCR method for species identification of coagulase-positive staphylococci. J Clin Microbiol 66: 765-769.

Schnellmann C, Gerber V, Rossano A, Jaquier V, Panchaud Y, Doherr MG, Thomann A, Straub R, Perreten $\mathrm{V}$ (2006) Presence of new mecA and $m p h(\mathrm{C})$ variants conferring antibiotic resistance in Staphylococcus spp. isolated from the skin of horses before and after clinic admission. J Clin Microbiol 44: 4444-4454.

Schwarz S, Kadlec K, Strommenger B (2008) Methicillin-resistant Staphylococcus aureus and Staphylococcus pseudintermedius detected in the BfT-GermVet monitoring programme 2004-2006 in Germany. J Antimicrob Chemother 61: 282-285.

Scientific Advisory Group on Antimicrobials of the Committee for Medicinal Products for Veterinary Use (SAGAM) (2009) Reflection paper on the use of third and fourth generation cephalosporins in food producing animals in the European Union: development of resistance and impact on human and animal health. J Vet Pharmacol Ther 32: 515-533.

Seputiene V, Bogdaite A, Ruzauskas M, Suziedeliene E (2012) Antibiotic resistance genes and virulence factors in Enterococcus faecium and Enterococcus faecalis from diseased farm animals: pigs, cattle and poultry. Pol J Vet Sci 15: 431-438.

Stegmann R, Burnens A, Maranta CA, Perreten V (2010) Human infection associated with methicillin-resistant Staphylococcus pseudintermedius ST71. J Antimicrob Chemother 65: 2047-2048.

van Duijkeren E, Catry B, Greko C, Moreno MA, Pomba MC, Pyörälä S, Ruzauskas M, Sanders P, Threlfall EJ, Torren-Edo J, Törneke K (2011) Review on methicillin-resistant Staphylococcus pseudintermedius. J Antimicrob Chemother 66: 2705-2714.

van Hoovels L, Vankeerberghen A, Boel A, van Vaerenbergh K, De Beenhower H (2006) First case of Staphylococcus pseudintermedius infection in a human. J Clin Microbiol 44: 4609-4612.

Weese JS, van Duijkeren E (2010) Methicillin-resistant Staphylococcus aureus and Staphylococcus pseudintermedius in veterinary medicine. Vet Microbiol 140: 418-429.

Windahl U, Reimegard E, Holst BS, Egenvall A, Fernstrom L, Fredrikkson M, Tronwald-Wigh G, Andersson UG (2012) Carriage of methicillin-resistant Staphylococcus pseudintermedius in dogs - a longitudinal study. BMC Vet Res 8: 34. 